\title{
Hubungan Lama Menjalani Hemodialisis dengan Kualitas Hidup Pasien Penyakit Ginjal Kronik dengan Diabetes Melitus di RSUP Dr. M Djamil Padang
}

\author{
Putri Wahyuni ${ }^{1}$, Saptino Miro ${ }^{2}$, Eka Kurniawan ${ }^{3}$
}

\begin{abstract}
Abstrak
Terapi hemodialisis pada pasien penyakit ginjal kronik membutuhkan waktu yang lama, memiliki komplikasi dan membutuhkan kepatuhan pasien. Hal ini akan memberikan stressor fisiologis dan psikologis pasien yang kemudian akan mempengaruhi kualitas hidup pasien. Tujuan penelitian ini adalah menentukan hubungan lama menjalani hemodialisis dengan kualitas hidup pasien penyakit ginjal kronik dengan diabetes melitus di RSUP Dr. M. Djamil Padang. Jenis penelitian ini adalah analitik observassional dengan pendekatan cross sectional yang melibatkan tiga puluh satu responden pasien penyakit ginjal kronik dengan diabetes melitus yang menjalani hemodialisis. Data di analisis dengan uji Chi-square. Teknik pengumpulan data menggunakan kuesioner KDQOL SF 1.3. Berdasarkan hasil penelitian didapatkan tujuh belas pasien (54,8\%) yang menjalani hemodialisis kurang dari dua belas bulan dan empat diantaranya memiliki kualitas hidup yang baik dan tiga belas lainnya memiliki kualitas hidup yang buruk. Hasil uji statistik didapatkan nilai $p=0,022(p<0,05)$. Disimpulkan bahwa terdapat hubungan yang bermakna antara lama menjalani hemodialisis dengan kualitas hidup pasien penyakit ginjal kronik dengan diabetes melitus.
\end{abstract}

Kata kunci: penyakit ginjal kronik, hemodialisis, kualitas hidup

\begin{abstract}
Hemodialysis in chronic kidney disease is a theraphy that takes a long time, has complications, and requires patient compliance. This condition will provide physiological and psychological stressors of patients which can affects the quality of life of the patients. The objective of this study was to determine the relation between duration of hemodialysis and the quality of life patients chronic kidney disease with diabetes melitus in Dr. M. Djamil Hospital. The design of this research was analytical observassional with cross sectional study approach involving thirty one respondents with chronic kidney disease patients who undergoing hemodialysis. The data was analyzed with Chisquare test. This study used primary data obtained by questionnaires Kidney Disease Quality Of Life Short Form 1.3 (KDQOL SF 1.3). Based on the result of this research there were seventeen patients (54,8\%) who undergoing hemodialysis for less than twelve months and four of them have a good quality of life and thirteen others have a poor quality of life. Statistical test results $p$ value $=0,022(p<0,05)$. The conclusion is the significant correlation between duration of hemodialysis and the quality of life patients chronic kidney disease with diabetes melitus.
\end{abstract}

Keywords: chronic kidney disease, hemodialysis, quality of life.

Affiliasi penulis: 1. Prodi Kedokteran Fakultas Kedokteran Universitas Andalas Padang (FK Unand), 2. Bagian IImu Penyakit Dalam FK Unand, 3. Bagian IImu Penyakit Dalam FK Unand

Korespondensi: Putri Wahyuni, Email: putriwahyuni96@ymail.com Telp: 081253060626

\section{PENDAHULUAN}

Chronic Kidney Disease (CKD) atau Penyakit Ginjal Kronik (PGK) adalah kerusakan ginjal selama tiga bulan atau lebih akibat abnormalitas struktur atau fungsi ginjal dengan atau tanpa penurunan laju filtrasi 
glomerulus (LFG) atau kadar LFG kurang dari 60 $\mathrm{mL} / \mathrm{menit} / 1,73 \mathrm{~m} 2$ lebih dari tiga bulan dengan atau tanpa kerusakan ginjal. ${ }^{1}$

Penyakit Ginjal Kronik (PGK) saat ini telah menjadi suatu masalah kesehatan di dunia. ${ }^{2}$ Menurut laporan United State Renal Disease Data System (USRDS) di Amerika Serikat, prevalensi PGK meningkat $20-25 \%$ setiap tahun. United States Renal Data System (USRDS) mencatat bahwa terdapat 100.000 pasien baru setiap tahun di Amerika. ${ }^{3}$ Kondisi ini juga terjadi di Indonesia. Di Indonesia, PGK menjadi salah satu penyakit yang masuk dalam 10 besar penyakit kronik. Perhimpunan Nefrologi Indonesia (Pernefri) melaporkan bahwa setiap tahun terdapat 200.000 kasus baru PGK stadium akhir. ${ }^{2}$ Menurut data Riskesdas tahun 2013 prevalensi PGK di Sumatera Barat sebanyak 0,2\%. ${ }^{4}$ Berdasarkan data yang diperoleh dari rekam medik di RSUP Dr. M. Djamil Padang pada tahun 2016 terdapat 2937 pasien PGK dengan rawat jalan dan 586 pasien PGK dengan rawat inap. Jumlah ini terus meningkat hingga September tahun 2017 yaitu terdapat 7801 pasien PGK dengan rawat jalan dan 911 pasien PGK dengan rawat inap. ${ }^{5}$

PGK diklasifikasikan menjadi lima stadium. Stadium ke-5 merupakan stadium akhir dari PGK atau disebut juga dengan end-stage renal disease (ESRD). Pada ESRD nilai LFG kurang dari $15 \mathrm{ml} / \mathrm{mnt}$, sehingga memerlukan terapi pengganti ginjal berupa peritoneal dialisis, transplantasi ginjal atau hemodialisis (HD). ${ }^{6}$ Hemodialisis adalah salah satu pilihan terapi pada pasien ESRD. ${ }^{1}$

Menurut data yang diperoleh dari bagian rekam medik RSUP Dr. M. Djamil Padang, pada tahun 2016 terdapat 2096 pasien yang menjalani hemodialisis dengan rawat jalan dan 11 pasien yang menjalani HD dengan rawat inap, sedangkan pada bulan Januari hingga September 2017 terdapat 6472 pasien yang menjalani HD dengan rawat jalan dan 0 pasien yang menjalani HD dengan rawat inap. ${ }^{5}$

Tujuan utama dari HD adalah menggantikan fungsi ginjal sehingga mampu mempertahankan homeostasis tubuh manusia. Terapi HD yang memerlukan waktu jangka panjang akan mengakibatkan munculnya beberapa komplikasi yaitu hipotensi dan kram otot, komplikasi tersebut dapat memberikan stressor fisiologis kepada pasien. ${ }^{6}$ Selain mendapatkan stressor fisiologis, pasien yang menjalani HD juga mengalami stressor psikologis. Stressor psikologis tersebut diantaranya adalah pembatasan cairan, pembatasan konsumsi makanan, gangguan tidur, ketidakjelasan tentang masa depan, pembatasan aktivitas rekreasi, penurunan kehidupan sosial, pembatasan waktu dan tempat bekerja, serta faktor ekonomi. ${ }^{7}$ Pasien akan kehilangan kebebasan karena berbagai aturan dan sangat bergantung kepada tenaga kesehatan, kondisi ini mengakibatkan pasien tidak produktif, pendapatan akan semakin menurun atau bahkan hilang. Sehingga hal tersebut dapat memengaruhi kualitas hidup. ${ }^{8}$

Kualitas hidup adalah istilah yang digunakan untuk menggambarkan rasa kesejahteraan, termasuk aspek kebahagiaan, kepuasan hidup dan sebagainya. Kualitas hidup pasien HD dipengaruhi oleh beberapa faktor, diantaranya adalah umur, jenis kelamin, pendidikan, pekerjaan, penyakit dasar PGK, komorbid, status nutrisi, penatalaksanaan medis dan lama menjalani HD. ${ }^{9}$

Semakin lama seorang pasien menjalani HD berbanding terbalik dengan kualitas hidup pasien. Hal ini dikarenakan tingkat kekhawatiran serta stres pasien yang semakin meningkat karena berpikir seharusnya HD dapat menyembuhkan penyakitnya. ${ }^{10}$ Penelitian Nurchayati (2010) menyebutkan semakin lama pasien menjalani HD, maka pasien semakin patuh untuk menjalani HD karena biasanya pasien telah mencapai tahap menerima dan kemungkinan pasien telah banyak mendapatkan pendidikan kesehatan dari perawat dan juga dokter tentang penyakit dan pentingnya menjalani HD secara teratur. ${ }^{8}$

Faktor lain yang memengaruhi kualitas hidup pasien HD adalah penyakit penyerta. ${ }^{9}$ Penelitian yang dilakukan oleh Pakpour et al (2010) diketahui 66\% dari 250 pasien HD memiliki penyakit penyerta. ${ }^{11}$ Prevalensi penyakit penyerta tertinggi pada pasien HD yaitu hipertensi, Diabetes Melitus (DM), glomerulopati primer, dan pielonefritis kronik. ${ }^{2}$ Colvy (2010) dalam penelitiannya mengatakan bahwa hingga $50 \%$ pasien memiliki penyakit penyerta seperti DM. ${ }^{12}$ 
DM sudah mencapai proporsi terbanyak di negara berkembang, termasuk di Indonesia. Indonesia memiliki tingkat prevalensi DM tertinggi keempat setelah India, Cina dan Amerika Serikat. ${ }^{13}$ Hiperglikemik kronik pada DM berkontribusi terhadap munculnya berbagai komplikasi, kerusakan jangka panjang, disfungsi dan kegagalan berbagai organ seperti mata, saraf, jantung, pembuluh darah dan ginjal. ${ }^{14}$ Penderita diabetes dibandingkan dengan nondiabetes memiliki kecenderungan 17 kali terjadi PGK. ${ }^{14}$

Pasien PGK yang disertai dengan DM akan membuat kondisi pasien semakin buruk karena menyebabkan keterbatasan dalam melakukan aktivitas sehari-hari dan kemampuan untuk bekerja. Insulin ataupun obat oral antidiabetik, pengawasan gula darah secara terus menerus dan pembatasan diet juga memengaruhi kualitas hidup pasien PGK dengan DM. $^{15}$

Penelitian yang dilakukan oleh Utami pada tahun 2014 di RSUD Tugurejo Semarang menyatakan bahwa terdapat hubungan antara lama menjalani HD dengan kualitas hidup pasien. ${ }^{16}$ Namun terdapat juga beberapa penelitian yang menyatakan tidak terdapat hubungan antara lama menjalani hemodialisis dengan kualitas hidup pasien. Penelitian yang dilakukan oleh Rahman et al pada tahun 2016 di RSUP. Prof. DR. R. D. Kondou Manado menyatakan bahwa tidak terdapat hubungan antara lama menjalani HD dengan kualitas hidup pasien. $^{17}$

Berdasarkan latar belakang di atas, maka perlu dilakukan penelitian mengenai hubungan lama menjalani terapi HD dengan kualitas hidup pasien PGK dengan DM di RSUP Dr. M. Djamil Padang.

\section{METODE}

Jenis penelitian ini adalah studi analitik observasional dengan rancangan cross sectional. Variabel independen adalah lamanya menjalani terapi HD, sedangkan variabel dependen adalah kualitas hidup pada pasien PGK dengan DM. Penelitian dilakukan pada bulan Februari 2018 di Instalasi Hemodialisis RSUP Dr. M Djamil Padang.
Populasi penelitian ini adalah semua pasien PGK dengan DM yang menjalani HD di Instalasi Hemodialisis RSUP Dr. M. Djamil Padang. Sampel penelitian yang dipilih adalah subjek yang diambil dari populasi studi yang memenuhi kriteria inklusi dan tidak memiliki kriteria eksklusi. Kriteria inklusi subjek: usia lebih dari 18 tahun, pasien bersedia menjadi subjek penelitian, pasien PGK dengan DM rawat jalan dan rawat inap yang menjalani $\mathrm{HD}$ rutin dan pasien dalam kesadaran compos mentis cooperatif. Kriteria eksklusi subjek: usia lebih dari 65 tahun, memiliki gangguan indra pendengaran atau penglihatan dan pasien dengan gangguan psikiatri.

Hasil studi diperoleh dengan cara wawancara menggunakan kuesioner. Kuesioner yang digunakan adalah Kidney Disease Quality of Life Short Form 1.3 (KDQOL-SF 1.3) untuk menentukan kualitas hidup pasien PGK dengan DM yang menjalani HD.

Data dianalisis secara statistik berdasarkan variabel yang dinilai menggunakan sistem komputerisasi yaitu analisis univariat dan bivariat. Analisis univariat dilakukan untuk melihat distribusi frekuensi dari masing-masing variabel independen dan variabel dependen. Analisis bivariat dilakukan untuk menganalisis hubungan antara variabel independen dan variabel dependen. Hubungan dua variabel tersebut dianalisis dengan menggunakan uji Chisquare dan dikatakan bermakna bila $p<0,05$.

\section{HASIL}

Penelitian ini dilakukan terhadap 31 orang pasien PGK dengan DM yang menjalani hemodialisis di RSUP Dr. M. Djamil Padang pada bulan Februari 2018.

\section{Karakteristik Responden}

Berdasarkan Tabel 1 menunjukkan bahwa sebagian besar responden berjenis kelamin laki-laki yaitu 17 orang $(54,8 \%)$, dan 14 orang berjenis kelamin perempuan (45,2\%). Responden dengan usia $<45$ tahun sebanyak 2 orang $(6,5 \%)$, usia $45-60$ tahun sebanyak 23 orang $(74,1 \%)$ dan usia $>60-65$ tahun sebanyak 6 orang $(19,4 \%)$. 
Tabel 1. Distribusi frekuensi karakteristik pasien PGK dengan DM yang menjalani HD berdasarkan jenis kelamin, usia, tingkat pendidikan dan pekerjaan di RSUP Dr. M. Djamil Padang.

\begin{tabular}{|c|c|c|c|}
\hline No & Karakteristik & $f$ & $\%$ \\
\hline \multirow[t]{4}{*}{1} & Jenis Kelamin & & \\
\hline & a. Laki-laki & 17 & 54,8 \\
\hline & b. Perempuan & 14 & 45,2 \\
\hline & Jumlah & 31 & 100 \\
\hline \multirow[t]{5}{*}{2} & Usia & & \\
\hline & a. $<45$ tahun & 2 & 6,5 \\
\hline & b. $\quad 45-60$ tahun & 23 & 74,1 \\
\hline & c. $>60-65$ tahun & 6 & 19,4 \\
\hline & Jumlah & 31 & 100 \\
\hline \multirow[t]{6}{*}{3} & Tingkat pendidikan & & \\
\hline & a. SD & 4 & 12,9 \\
\hline & b. SMP & 3 & 9,7 \\
\hline & c. SMA & 15 & 48,4 \\
\hline & d. Perguruan Tinggi (PT) & 9 & 29 \\
\hline & Jumlah & 31 & 100 \\
\hline \multirow[t]{4}{*}{4} & Pekerjaan & & \\
\hline & a. Bekerja & 13 & 41,9 \\
\hline & b. Tidak bekerja & 18 & 58,1 \\
\hline & Jumlah & 31 & 100 \\
\hline
\end{tabular}

Responden yang berpendidikan SD sebanyak 4 orang (12,9\%), berpendidikan SMP sebanyak 3 orang $(9,7 \%)$, berpendidikan SMA sebanyak 15 orang (48,4\%), dan Perguruan Tinggi (PT) sebanyak 9 orang (29\%). Responden yang tidak bekerja lebih banyak yaitu 18 orang $(58,1 \%)$, dan responden yang bekerja yaitu 13 orang $(41,9 \%)$.

\section{Distribusi Lama Menjalani Hemodialisis pada Pasien PGK dengan DM}

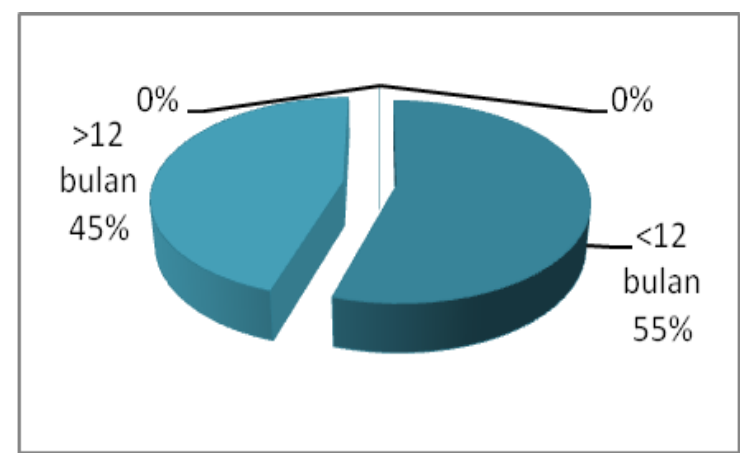

Gambar 1. Distribusi frekuensi lama menjalani hemodialisis pada pasien PGK dengan DM di RSUP Dr. M. Djamil Padang.
Pada penelitian ini didapatkan bahwa sebagian besar responden menjalani HD $<12$ bulan yaitu 17 orang $(54,8 \%)$ dan responden yang menjalani HD $>12$ bulan yaitu 14 orang $(45,2 \%)$.

\section{Distribusi Kualitas Hidup Pasien PGK dengan DM yang Menjalani Hemodialisis}

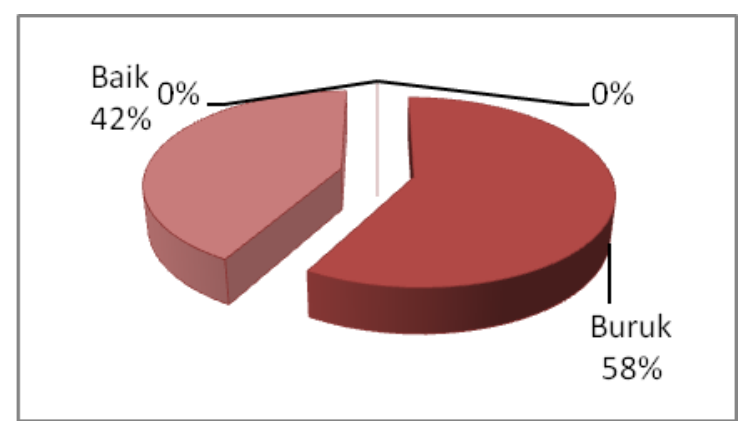

Gambar 2. Distribusi frekuensi kualitas hidup pasien PGK dengan DM yang menjalani HD di RSUP Dr. M. Djamil Padang.

Berdasarkan Gambar 2 dapat dilihat bahwa sebagian besar pasien memiliki kualitas hidup buruk yaitu sebanyak 18 orang $(58,1 \%)$ dan pasien yang memiliki kualitas hidup yang baik sebanyak 13 orang $(41,9 \%)$.

Hubungan Lama Menjalani Hemodialisis dengan Kualitas Hidup Pasien PGK dengan DM

Tabel 2. Hubungan lama hemodialisis dengan kualitas hidup pasien PGK dengan DM

\begin{tabular}{|c|c|c|c|c|c|c|c|}
\hline \multirow{3}{*}{$\begin{array}{l}\text { Lama } \\
\text { HD }\end{array}$} & \multicolumn{4}{|c|}{ Kualitas Hidup } & \multirow{2}{*}{\multicolumn{2}{|c|}{ Total }} & \multirow{3}{*}{$\mathbf{p}^{*}$} \\
\hline & \multicolumn{2}{|c|}{ Baik } & \multicolumn{2}{|c|}{ Buruk } & & & \\
\hline & $f$ & $\%$ & $f$ & $\%$ & $f$ & $\%$ & \\
\hline$<12$ bulan & 4 & 13 & 13 & 41,9 & 17 & 54,8 & \\
\hline$>12$ bulan & 9 & 29 & 5 & 16,1 & 14 & 45,2 & 0,022 \\
\hline Total & 13 & 42 & 18 & 58 & 31 & 100 & \\
\hline
\end{tabular}

Hasil uji statistik menggunakan Chi Square Test diperoleh nilai $p=0,022(p<0,05)$. Berdasarkan hasil tersebut dapat disimpulkan secara statistik bahwa terdapat hubungan yang bermakna antara lama hemodialisis dengan kualitas hidup pada pasien PGK dengan DM. 


\section{PEMBAHASAN}

Berdasarkan hasil analisis didapatkan nilai $p$ sebesar 0,022 $(<0,05)$ maka dapat diambil kesimpulan bahwa ada hubungan yang signifikan antara lama menjalani HD dengan kualitas hidup pada pasien PGK dengan DM di RSUP Dr. M. Djamil Padang. Hal ini sejalan dengan penelitian yang dilakukan oleh Nurchayati (2011) tentang analisis faktor-faktor yang berhubungan dengan kualitas hidup pasien PGK yang menjalani HD, dimana salah satu faktor tersebut adalah lamanya menjalani HD. Pada penelitian tersebut disebutkan bahwa didapatkan nilai $p$ sebesar $0,018(<0,05)$ artinya terdapat hubungan yang signifikan antara lama menjalani HD dengan kualitas hidup pasien PGK. ${ }^{8}$

Pada penelitian ini jumlah pasien yang menjalani HD lebih banyak pada $<12$ bulan yaitu sebanyak 17 orang (54,8\%). Hasil ini sesuai dengan hasil penelitian yang dilakukan Nurchayati (2011), dimana pasien yang belum lama ( $<10$ bulan) menjalani HD lebih banyak yaitu sebanyak 47 orang (49.5\%). ${ }^{8}$ Menurut Nurchayati (2011), semakin lama pasien menjalani HD maka pasien semakin patuh untuk menjalani HD karena biasanya responden telah mencapai tahap menerima ditambah mereka juga kemungkinan banyak mendapatkan pendidikan kesehatan dari perawat dan juga dokter tentang penyakit dan pentingnya melaksanakan HD secara teratur bagi mereka. ${ }^{8}$ Menurut penelitian Sompie et al (2015) pasien yang baru menjalani HD memiliki tingkat depresi yang bervariasi dari tidak ada depresi, depresi ringan, depresi sedang bahkan depresi berat, sedangkan pasien yang sudah lama menjalani hemodialisis tetap memiliki depresi tetapi hanya yang ringan saja. ${ }^{18}$

Dalam 31 orang responden, 18 diantaranya memiliki kualitas hidup yang buruk. Buruknya kualitas hidup responden diakibatkan oleh perjalanan penyakit PGK yang progresif dan stressor yang ditimbulkan selama terapi HD. Selain itu buruknya kualitas hidup responden juga diakibatkan oleh banyaknya penyakit penyerta yang terdapat pada pasien HD, salah satunya adalah DM. Menurut penelitian yang dilakukan oleh Utami (2016) disebutkan bahwa kualitas hidup pasien yang menjalani HD dengan DM lebih buruk jika dibandingkan dengan pasien yang menjalani HD tanpa DM. Pasien HD tanpa DM memiliki kualitas hidup yang baik 4,230 kali dibandingkan dengan pasien HD yang disertai DM dan pasien HD dengan DM memiliki risiko kematian 6,714 kali dibandingkan dengan pasien HD tanpa DM. ${ }^{19} \mathrm{Hal}$ ini terjadi karena DM memberikan pengaruh ke berbagai organ tubuh seperti gangguan fungsi penglihatan, penyakit jantung, kerusakan ginjal, penyakit serebrovaskuler dan vaskuler perifer, hingga amputasi. Keadaan ini menyebabkan keterbatasan dalam melakukan aktivitas sehari-hari dan kemampuan untuk bekerja. Insulin ataupun obat oral antidiabetik, pengawasan gula darah secara terus menerus, dan pembatasan diet memengaruhi kualitas hidup pasien. ${ }^{15} \mathrm{Hal}$ tersebut menyebabkan kondisi pasien HD semakin buruk karena komplikasi yang diakibatkan DM sehingga memengaruhi kualitas hidup pasien.

Kualitas hidup pasien yang menjalani HD seringkali menurun karena menyebabkan pasien terpaksa mengubah kebiasaan rutin hidupnya. Terutama bagi pasien yang belum lama menjalani HD, pasien merasa belum siap untuk menerima dan beradaptasi atas perubahan yang terjadi pada hidupnya. Ketidakmampuan, ketergantungan pada orang lain, biaya pengobatan dimana akan mengganggu aktifitas normal yang biasa dilakukan. Masalah ini akan memengaruhi aspek spiritual, psikologis, sosial dan keluarga dan seterusnya akan memengaruhi fisik, kognitif dan emosi pasien. Pada pasien juga terjadi penurunan otonomi, kehilangan identitas peran keluarga, terpisah dari keluarga, perasaan terisolasi, membutuhkan pertolongan, keterbatasan aktifitas fisik, diikuti oleh stressor lain berupa penurunan kontak sosial, dan ketidakpastian tentang masa depan. ${ }^{8}$

\section{SIMPULAN}

Mayoritas pasien PGK dengan DM memiliki kualitas hidup buruk.

Terdapat hubungan yang bermakna antara lama menjalani hemodialisis dengan kualitas hidup pasien PGK dengan DM. 


\section{DAFTAR PUSTAKA}

1. National Kidney Foundation - Kidney Disease Improving Global Outcomes (NKF-KDIGO). KDIGO 2012 clinical practice guideline for the evaluation and management of chronic kidney disease. ISN. 2013;3(1):1-163.

2. Perhimpunan Nefrologi Indonesia (Pernefri). Annual report of Indonesian renal registry. Pernefri. 2015;8:1-45.

3. United States Renal Data System [USRDS], National Institutes of Health [NIH] and National Institue of Diabetes and Digestive Kidney Disease [NIDDK]. 2009.

4. Departemen Kesehatan RI. Riset kesehatan dasar (Riskesdas) 2013. Badan Penelitian dan Pengembangan Kesehatan Indonesia (diunduh November 2017). Tersedia dari: http://www. depkes.go.id/resources/download/general/HasilRis kesdas2013.pdf

5. Instalasi Rekam Medik RSUP Dr. M. Djamil Padang. Data rekam medik penyakit ginjal kronik 2015 - September 2017 bagian rawat jalan dan rawat inap. Padang. RSUP Dr. M. Djamil Padang; 2017.

6. Suwitra K. Penyakit ginjal kronik. Dalam: Setiati S, Alwi I, Sudoyo AW, Simadibrata M, Setyohadi B, editor (penyunting). Buku ajar ilmu penyakit dalam. Edisi ke-6. Jakarta: Pusat Penerbitan Departemen IImu Penyakit Dalam FKUI. 2014;2161-67.

7. Tu HY, Shao JH, Wu FJ, Chen SH. Stressors and coping strategies of 20-45 year old hemodialysis patients. Collegian (Royal College of Nursing, Australia). 2014;21(3):1-8.

8. Nurcahayati S. Analisis faktor-faktor yang berhubungan dengan kualitas hidup pasien penyakit ginjal kronik yang menjalankan hemodialisa di Rumah Sakit Islam Fatimah Cilacap dan Rumah Sakit Umum Daerah Banyumas (tesis). Depok: Universitas Indonesia; 2010.

9. Yuwono A. Kualitas hidup menurut Spitzer pada penderita gagal ginjal terminal yang menjalani hemodialisis di unit hemodialisis RSUD Dr. Kariadi. (skripsi). Semarang: Universitas Diponegoro. 2000.

10. Anees M, Hammed F, Mumtaz A, Ibrahim M, Khan MNS. Dialysis-related factors affecting quality of life in patients on hemodialysis. Iranian Journal of Kidney Disease. 2011;5(1):9-14.

11. Pakpour A, Saffari M, Yekaninejad S, Panahi D, Harrison A, Moisted S. Health-related quality of life in a sample of Iranian patients in hemodialysis. Iranian Journal of Kidney Disease. 2010;4(1).

12. Colvy J. Tips cerdas mengenali dan mencegah gagal ginjal. Yogyakarta: DAFA Publishing; 2010.

13. Wild S, Roglic G, Green A, Sicree R, King H. Global prevalence of diabetes : estimates for the year 2000 and projection for 2030. Diabetes Care. 2004;27:1047-53.

14. Dabla PK. Renal function in diabetic nephropathy. World J Diabetes. 2010;1(2):48-56.

15. Sharf SA, El-Sebaee HA, Roshdy MM. Hemoglobin level, associated co-morbidities and quality of life among patients undergoing hemodialysis at one of the University Hospitals in Cairo Governorate. Word Applied Sciences Journal. 2013;23(1):29-36.

16. Utami OC. Hubungan antara lama menjalani hemodialisis dengan kualitas hidup pada pasien gagal ginjal kronik di RSUD Tugurejo Semarang (skripsi). Semarang: Universitas Muhammadiyah Semarang. 2014.

17. Rahman MTSA, Kaunang TMD, Elim C. Hubungan antara lama menjalani hemodialisis dengan kualitas hidup pasien yang menjalani hemodialisis di Unit Hemodialisis. Journal e-Clinic (eCl). 2016;4(1):36-40.

18. Sompie EM, Kaunang TMD, Munayang $H$. Hubungan antara lama menjalani hemodialisis dengan depresi pada pasien PGK di RSUP Prof. Dr. R. D. Kandou Manado. Journal e-Clinic (eCl). $2015 ; 3(1): 1-5$.

19. Utami MPS. Komorbiditas dan kualitas hidup pasien hemodialisa RS PKU Muhammadiyah (tesis). Yogyakarta: Universitas Muhammadiyah Yogyakarta. 2016. 